\title{
CFD modeling of artificial vortex air generator for green electric power
}

\author{
Ali A. Ismaeel ${ }^{1,2}$, Hussain H. Al-Kayiem ${ }^{1,}{ }^{*}$, Aklilu T. Baheta ${ }^{1}$ and Mohammed A. Aurybi ${ }^{1}$ \\ ${ }^{1}$ Department of Mechanical Engineering, Universiti Teknologi PETRONAS, 32610 Bandar Seri \\ Iskandar, Perak, Malaysia. \\ ${ }^{2}$ Department of Electromechanical Engineering, University of Technology, Baghdad, Iraq
}

\begin{abstract}
This paper presents and discusses a Computational Fluid Dynamics (CFD) simulation of artificial vortex air generator as part of the preliminary of Solar Vortex Power Generator for an electrical power generation. A vortex air generator system was built, consisting of concentric cylinders. The inner cylinder was fitted with stationary air guide vanes and covered at the top by a transparent plate to capture the solar radiation and create swirling updraft flow which is able to rotate wind turbine and produces power. The influence of inlet air velocity and temperature on the swirling strength and mass flow generated has been evaluated by validated CFD simulation. ANSYS Fluent software was adopted to solve the 3-D, steady state of Navier-Stokes and energy equations in cylindrical coordinate system integrated with discrete ordinates (DO) radiation model. For the preliminary vortex generator design, the CFD results were validated first with previous experimental measurements. Then the variable operation parameters were carried out on the proposed model. The simulation result demonstrated that inflow velocity is a key parameter for enhancing the system performance. By increasing the inflow velocity from $0.4 \mathrm{~m} / \mathrm{s}$ to 0.6 $\mathrm{m} / \mathrm{s}$ and inflow temperature $323^{\circ} \mathrm{k}$ the enhancement rate of the mass air flow generated reached to $26 \%$ compared with $7 \%$ when increase the inflow temperature to $328^{\circ} \mathrm{k}$ and inflow velocity $0.4 \mathrm{~m} / \mathrm{s}$.
\end{abstract}

\section{Introduction}

The concept of harvesting energy from extreme atmosphere like dust devils and tornado phenomena to produce a clean electric power as a new renewable energy source have been evaluated by many researchers in the time past and still $[1,2]$. This concept depends on a technique of generating an artificial updraft hot air like the vortex that transforms thermal energy into mechanical work during an upward heat convection motion of the air, which is similar to the idea of heat engine works [3]. To establish an artificial swirling air motion like a tornado, there are two considerable variables which must be implemented, i.e. circulation and updraft [4].

*Corresponding author: hussain kayiem@utp.edu.my 
The circulation is accomplished by getting the air tangentially in an inward direction using a mechanical swirling device such as (interior winding ribbing, screws, vortex tube, guide twirl vanes and others) [5]. Whereas, a approaches to build up the updraft vortex stream [6]. A heat source is utilized to upgrade the buoyancy forces of the hot air, such as the Solar Vortex Engine (SVE) was proposed by [7]. The SVE comprises of two main parts, solar air collector (SAC) and vortex engine (VE). The SVE has been developed by utilizing a new design for the guide vanes or deflectors inside the VE by using curvature deflectors to smooth and enhance the vortex generated by the engine [8]. For power generation, the axial flow turbine is located beneath the upstream of the air flow leaving the SAC at the base of the SVE. Although the SVE is a low-cost and simple configuration, but the drawback is the stack effect inside the vortex generator which is weak without the heat source to generate the initial vortex and maintain the updraft continuously. Thus, the enhancement and development concept of SVE using a simple construction design support was carried out in the Solar Research Site (SRS) at Universiti Teknologi PETRONAS - Malaysia. A new arrangement of artificial vortex generator (AVG) integrated with double solar absorbing units has been devised and hereby referred to as 'Solar Vortex Power Generator (SVPG)' model. The study objective is to investigate the effect of variable operating parameters on the swirling strength of the SVPG using CFD simulation. Also, to present brief description of the developed experimental model of the SVPG.

\section{Preliminary model of plant}

The preliminary model of SVPG comprises of main three parts. The greenhouse effect by the SAC converts the solar radiation to a kinetic energy in the air stream through a series of energy conversion processes and as a result, ambient air is heated and moves towards the artificial vortex generator (AVG) part.

The solar heat trap unit (SHT) consists of the transparent upper cover (TUC) with a transparent structure part, used as a source to establish the initial convective vortex by capturing the solar energy that is used to heat the air inside the AVG. Thus, creates the updraft flow while withdrawing hot air from the SAC to the AVG. Acceleration of the air flow through guide vanes imposes rotational swirling motion inside the AVG. In order to generate electricity, vertical - wind turbine with electric generator can be added in the path of vortexinduced flow, extracts kinetic energy and produces power. The detailed configurations of the preliminary design of SVPG are shown in the Figure 1. AVG has diameter and height of the inner cylinder were of 0.9 and $0.6 \mathrm{~m}$, respectively. Diameter and height of the outer cylinder are 1 and $0.6 \mathrm{~m}$, respectively. The guide vanes were set to $25^{\circ}$ with a height of $0.3 \mathrm{~m}$ and length of $0.35 \mathrm{~m}$. The entry slot width was $0.1 \mathrm{~m}$ with the height of $0.3 \mathrm{~m}$. While the dimensions of TS was $0.6 \mathrm{~m}$ in height having a polygon shape and the diameter of the TUC was $0.1 \mathrm{~m}$ with the hole of $0.3 \mathrm{~m}$ in diameter at its center.

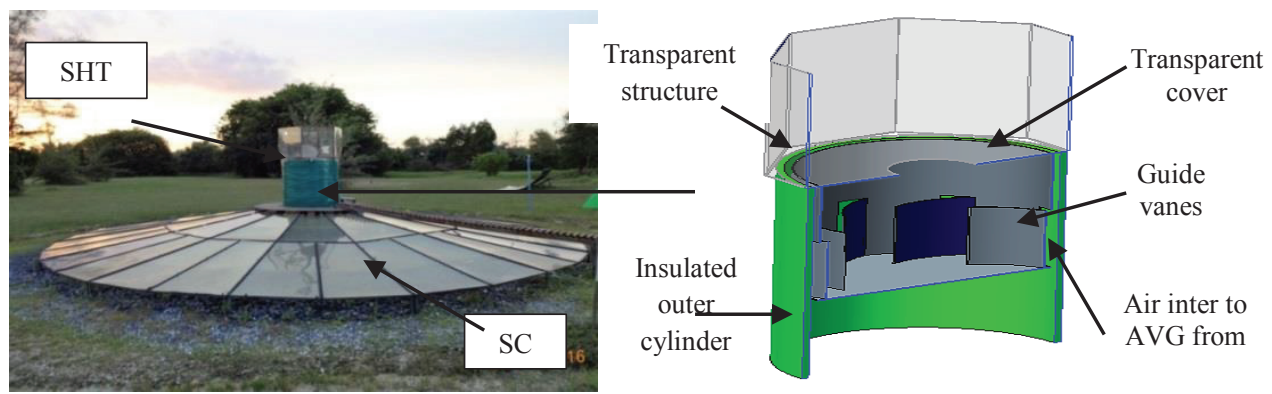

Fig. 1. Preliminary model of SVPG 


\section{Numerical investigation}

\subsection{Numerical Simulation Methods}

Simulation using Fluent and the Boussinesq model for natural convection [9] was employed in this study. This model assumes that density remains a constant value in all solved equations, except for the buoyancy term in the momentum equation. Simulations were conducted based on $k-\varepsilon$ turbulence model with RNG. The Semi Implicit Method for Pressure Linked Equation - Consistent (SIMPLEC) algorithm was applied for second order discretization for pressure; momentum and energy obtain more converged solution. The Discrete Ordinates (DO) have been applied under the radiation model to represent the solar radiation load passing through the transparent Perspex to heat up the air underneath. The amount of radiation is highly dependent on the solar insolation available and the values were obtained from solar calculator pre-build in ANSYS Fluent 15. The (DO) method calculates the direct and diffuse intensity of the sun depending on the location of the plant related to the sun at a specified time and location which limited by the user, so there is a solar calculator to specify the directions and solar values.

\subsection{Governing Equations}

Various working principle and governing equations have been applied in numerical simulation done with ANSYS Fluent 15 . Some of the examples are conservation of continuity equation and momentum, energy balance equations which have been applied to study the flow field within VAG as follows [10]:

Continuity equation:

$$
\left(\frac{\partial u}{\partial x}+\frac{\partial v}{\partial y}+\frac{\partial w}{\partial z}\right)=0
$$

Momentum equation:

$$
\begin{aligned}
& \rho \nabla \cdot(u V)=-\frac{\partial p}{\partial x}+\frac{\partial \tau_{x x}}{\partial x}+\frac{\partial \tau_{y x}}{\partial y}+\frac{\partial \tau_{z x}}{\partial z}+S_{x} \\
& \rho \nabla \cdot(v V)=-\frac{\partial p}{\partial y}+\frac{\partial \tau_{x y}}{\partial x}+\frac{\partial \tau_{y y}}{\partial y}+\frac{\partial \tau_{z y}}{\partial z}+S_{y} \\
& \rho \nabla \cdot(w V)=-\frac{\partial p}{\partial z}+\frac{\partial \tau_{x z}}{\partial x}+\frac{\partial \tau_{y z}}{\partial y}+\frac{\partial \tau_{z z}}{\partial z}+S_{z}
\end{aligned}
$$

The source terms $S_{x}, S_{y}$, and $S_{z}$ in (2a), (2b) and (2c) represent the body force.

An equation (3) the Boussinesq model is used by setting up the problem with fluid density as a function of temperature.

$$
(\rho)=\rho_{\circ}(1-\beta \Delta T)
$$

Equation (3) is valid for $(1-\beta \Delta T) \ll 1$

Turbulence model:

$$
\rho \frac{\partial}{\partial x_{i}}\left(k u_{i}\right)=\frac{\partial}{\partial x_{j}}\left(\alpha_{k} \mu_{e f f} \frac{\partial k}{\partial x_{j}}\right)+G_{k}+G_{b}-\rho \varepsilon-Y_{M}
$$




$$
\rho \frac{\partial}{\partial x_{i}}\left(\varepsilon u_{i}\right)=\frac{\partial}{\partial x_{j}}\left(\alpha_{\varepsilon} \mu_{e f f} \frac{\partial \varepsilon}{\partial x_{j}}\right)+G_{1 \varepsilon} \frac{\varepsilon}{k}\left(G_{k}+C_{3 \varepsilon} G_{b}\right)-C_{2 \varepsilon} \rho \frac{\varepsilon^{2}}{k}-R_{\varepsilon}
$$

Energy equation:

$$
\rho C_{p}\left(\frac{\partial(u T)}{\partial x}+\frac{\partial(v T)}{\partial y}+\frac{\partial(w T)}{\partial z}\right)=k\left(\frac{\partial^{2} T}{\partial x^{2}}+\frac{\partial^{2} T}{\partial y^{2}}+\frac{\partial^{2} T}{\partial z^{2}}\right)+S_{E}
$$

The radiation equation which is solved by the software can be written as:

$$
\nabla .\left(I_{\lambda}(\vec{r}, \vec{s}) \vec{s}\right)+\left(a_{\lambda}+\sigma_{s}\right) I_{\lambda}(\vec{r}, \vec{s})=a_{\lambda} n^{2} I_{b \lambda}+\frac{\sigma_{s}}{4 \pi} \int_{0}^{4 \pi} I_{\lambda}(\vec{r}, \vec{s}) \varphi\left(\vec{s} . \vec{s}^{\prime}\right) d \Omega^{\prime}
$$

The solar intensity in each direction $\vec{S}$ and position $\vec{r}$ can be written as follows [11]:

$$
I_{\lambda}(\vec{r}, \vec{s})=\sum_{k} I_{\lambda}(\vec{r}, \vec{s}) \Delta \lambda_{k}
$$

$\vec{r}=$ position vector, $\vec{s}=$ direction vector, $\vec{s}=$ scattering direction vector, $\alpha=$ absorption coefficient, $n=$ refractive index, $\sigma_{s}=$ scattering coefficient, $\sigma=$ Stefan-Boltzmann constant $\left(5.669 \times 10^{-8} \mathrm{~W} / \mathrm{m}^{2} \cdot \mathrm{K}^{4}\right), \quad I=$ radiation intensity, which depends on $\vec{r}$ And $\vec{s}$, $T=$ temperature, $\phi=$ face function, $\hat{\Omega}=$ solid angle, $\lambda=$ wave length, $\alpha_{\lambda}=$ spectral absorption coefficient, $I_{b \lambda}=$ black body intensity, $\mathrm{S}_{\mathrm{h}}=$ Heat source due to incident solar radiation, $\mathrm{G}_{\mathrm{k}}=$ Production of turbulent kinetic energy, $\mathrm{G}_{\mathrm{b}}=$ Generation of turbulence kinetic energy due to buoyancy, $\mathrm{C}_{3 \varepsilon}=$ constant to calculate the degree of $\varepsilon$ effected by buoyancy.

\subsection{Boundary Conditions and Simulation Parameter Cases}

The values of the boundary conditions considered as an input parameter in the CFD simulation were all adopted from the previous experimental measurements, as illustrated in Tables 1 and 2.

Table1. Thermal properties of materials

\begin{tabular}{|l|c|c|}
\hline Thermal property & Perspex & Aluminium \\
\hline Properties & $\begin{array}{c}\text { Solid, Semi- } \\
\text { transparent }\end{array}$ & Solid ,Opaque \\
\hline Thermal conductivity $(\mathrm{w} . \mathrm{m} / \mathrm{k})$ & 0.189 & 202.4 \\
\hline Density $\left(\mathrm{kg} / \mathrm{m}^{3}\right)$ & 1200 & 2719 \\
\hline Specific heat $(\mathrm{J} / \mathrm{kg} . \mathrm{k})$ & 1200 & 871 \\
\hline
\end{tabular}

Table 2. Initial boundary conditions from experimental preliminary model

\begin{tabular}{|l|c|c|c|}
\hline $\begin{array}{c}\text { Surfaces } \\
\text { components }\end{array}$ & $\begin{array}{c}\text { No. of } \\
\text { item }\end{array}$ & $\begin{array}{c}\text { Boundary } \\
\text { type }\end{array}$ & Boundary conditions \\
\hline $\begin{array}{l}\text { Transparent } \\
\text { structure }\end{array}$ & 1 & Wall & Material= Perspex $\mathrm{T}=322.7 \mathrm{~K}^{\circ}$ \\
\hline Upper cover & 1 & Wall & Material= Perspex $\mathrm{T}=322.7 \mathrm{~K}^{\circ}$ \\
\hline Upper cover hole & 1 & Outflow & Opening hole, $\mathrm{D}=0.3 \mathrm{~m}$ \\
\hline Inner cylinder & 1 & Wall & Material= Aluminium $\mathrm{T}=330 \mathrm{~K}^{\circ}$ \\
\hline Guide vanes & 8 & Wall & Material= Aluminium $\mathrm{T}=330 \mathrm{~K}^{\circ}$ \\
\hline Air entry slots & 8 & Velocity-inlet & $\begin{array}{c}\mathrm{V}=0.4 \mathrm{~m} / \mathrm{s} \\
\mathrm{T}=323 \mathrm{~K}^{\circ}\end{array}$ \\
\hline Ambient condition & - & - & $\begin{array}{c}\mathrm{T}=309 \mathrm{~K}^{\circ} \\
\mathrm{S}=1000 \mathrm{~W} / \mathrm{m}^{2}\end{array}$ \\
\hline
\end{tabular}




\subsection{Grid Independence}

Grid independence is considered in the solution; five mesh sizes were used, tetrahedral cell sizes range between $(0.05 \mathrm{~m}-0.005 \mathrm{~m})$ is tested and logically the used of fine mesh with a minimum mesh size gave a more accurate solution, however, implies more computer cost and time. The mesh size (maximum $0.01 \mathrm{~m}$ and minimum $0.001 \mathrm{~m}$ ) was used by percentage error $(3.2 \%)$ for velocity and temperature $(2.1 \%)$ for the preliminary model and they are acceptable.

\section{Result and discussion}

To validate the CFD assessment, the comparison of the CFD results with the preliminary experimental measurements was made. The outflow swirl updraft was considered as the main parameter for validation. The contours velocity magnitude distribution of the initial case is shown in Fig. 2a. From the figures, the average outlet velocity $(1.85 \mathrm{~m} / \mathrm{s})$ was simulated at the center of the upper hole; the value obtained is in close agreement with the experimental measurement at the same inflow velocity condition $(0.4 \mathrm{~m} / \mathrm{s})$ with percentage error of $3.2 \%$. Whereas, the maximum velocity magnitude achieved was $(2.3 \mathrm{~m} / \mathrm{s})$ and occurred at $20 \mathrm{~cm}$ above the upper hole at the both ends of the vortex streams within the SHT. As the electric power generation is the main objective from SVPG, it is recommended for setting the turbine unit in this position to convert the peak velocity of vortices generated by the work.

\subsection{Analyses of Vortex Flow Structure}

Simulations the vortex flow behavior within the AVG \& SHT are shown in Figure 2.b The Figure describes the outflow direction from the vanes as a slope vector along the guide vane height. Then, moves towards the upper hole with a small circulation motion like a convection currents as it begins to appear at the end of guide height in the bottom corner of the upper cover within the AVG. After the upper hole, the swirl flow structure diverges into two streams that are extended into SHT with the formation of convection currents around the swirl flow. The reason for the formation of the convection currents is due to the contact of the air inside the AVG and SHT with the hot surfaces in the SHT components.
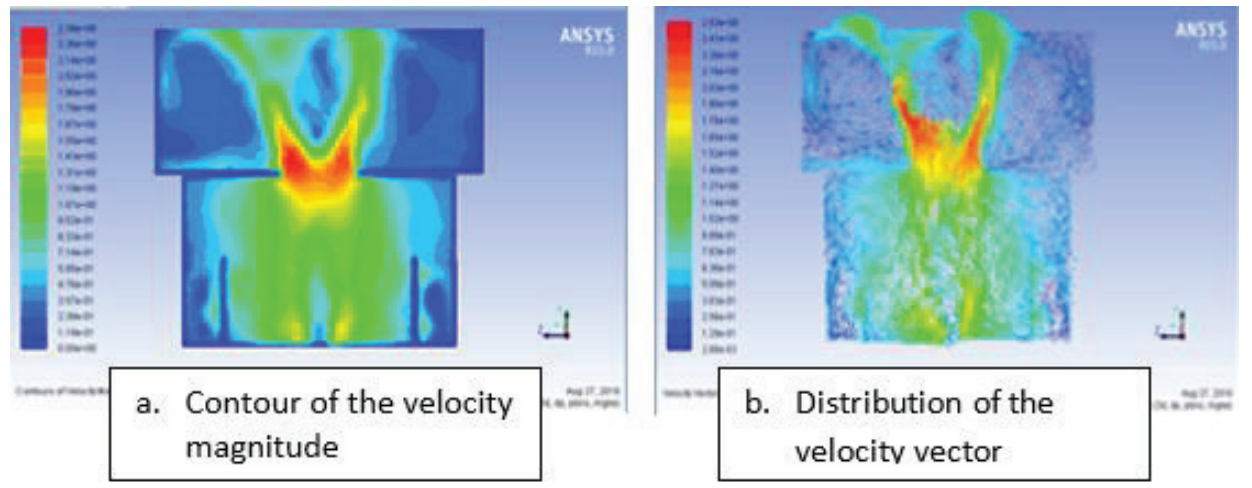

Fig. 2. Velocity distribution within AVG and SHT for the initial case. 


\subsection{Analyses of Initial Condition Parameters}

The result of the mass flow rate and swirl updraft velocity generated in the different initial boundary conditions are listed in Table 3 . It is clearly observed that there is a significant improvement in the swirl strength emerging from AVG when the air velocity is increased from the SC to AVG. Thus, swirl strength is enhanced; indicating an increase in the mass flow generated which translate to more electrical power extracted by the turbine. The CFDresults, obtained showed an enhancement in the buoyancy force into AVG because of the increased initial inflow temperature. Also, increasing the inner wall temperature of AVG cylinder contributes to the improvement in outlet velocity and the flow rate. However, this improvement is less compared with extended the inflow velocity state. On the other hand, the change of the initial parameters does not effect on the vortex structure within the VAG and SHT as shown in Figures.3. The flow behavior is observed to remain same in the initial case.

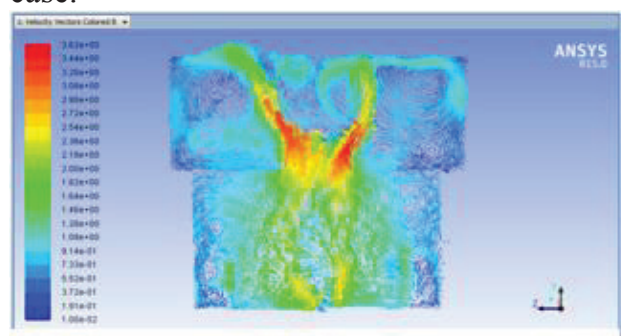

a. Velocity vectors for inflow velocity $=0.6 \mathrm{~m} / \mathrm{s}$

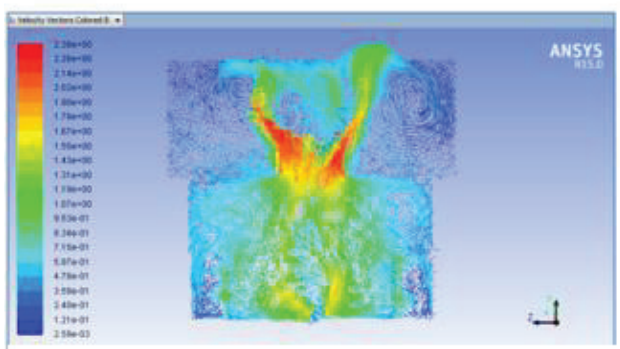

c. Velocity vectors for inflow Temp $=328 \mathrm{~K}$

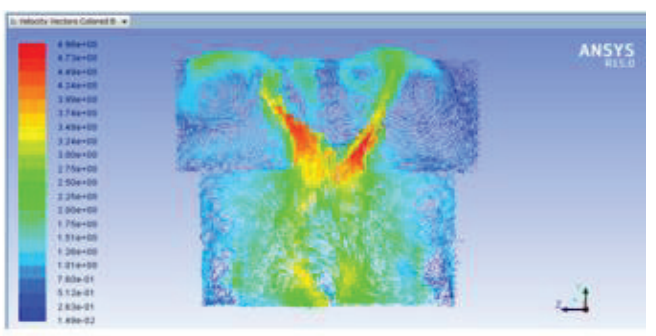

b. Velocity vectors for inflow velocity $=0.8 \mathrm{~m} / \mathrm{s}$

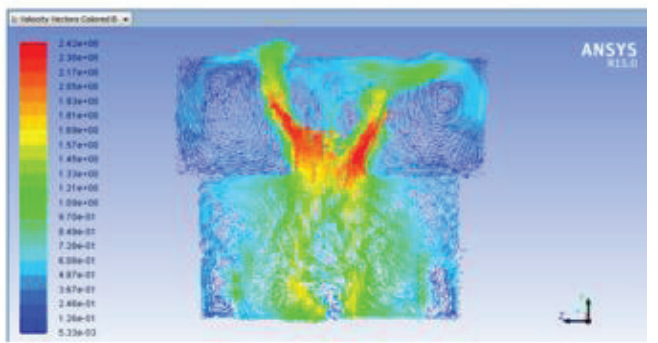

d. Velocity vectors for AVG wall Temp $=335 \mathrm{~K}$

Fig. 3. Section of vortex structure within AVG and SHT in different boundary conditions.

Table 3. Result of the mass flow and swirl updraft velocity generated in the variables initial condition

\begin{tabular}{|l|c|c|c|c|}
\hline \multicolumn{1}{|c|}{ Cases } & $\begin{array}{c}\text { Inflow } \\
\text { Velocity } \\
\text { (m/s) }\end{array}$ & $\begin{array}{c}\text { Swirl } \\
\text { updraft } \\
\text { strength } \\
\text { (m/s) }\end{array}$ & $\begin{array}{c}\text { Mass } \\
\text { flow rate } \\
\mathbf{( K g / s )}\end{array}$ & $\begin{array}{c}\text { Enhancement of } \\
\text { mass flow (\%) } \\
\text { compared with } \\
\text { initial case }\end{array}$ \\
\hline Initial case & 0.4 & 1.85 & 0.1595 & - \\
\hline \multirow{2}{*}{ Increase the inflow velocity } & 0.6 & 2.5 & 0.2155 & 26 \\
\cline { 2 - 5 } & 0.8 & 3.2 & 0.2759 & 42 \\
\hline $\begin{array}{l}\text { Increase the inflow temperature } \\
\text { from 323 K to 328 K }\end{array}$ & 0.4 & 2 & 0.1724 & 7.4 \\
\hline $\begin{array}{l}\text { Increase the inner wall } \\
\text { temperature from 330K to 335K }\end{array}$ & 0.4 & 1.97 & 0.1698 & 6 \\
\hline
\end{tabular}




\section{Conclusions}

In this paper, modeling of artificial vortex generator (AVG) supported by transparent cover has been simulated computationally by using ANSYS FLUENT 15. The AVG is the main part of SVPG model that was proposed as a new system in the solar vortex updraft field for renewable power generation. The impact of the operating parameter on the swirl updraft flow characteristics was investigated and the results were compared with preliminary experimental measurements. For a given geometry of the AVG, The CFD results showed that increasing the inflow air velocity is more efficient to enhance the mass flow rate generated and extract power production compared to increase the air flow temperature.

The authors would like to acknowledge Universiti Teknologi PETRONAS for the technical and financial support to conduct this research. Also, the authors express their gratitude to The Ministry of Higher Education - Malaysia for permitting the utilization of the measuring instrumentations purchased under the FRGS/2015/1 grant under CS: 0153AB-K81.

\section{References}

1. S. Nizetic. Energy, 36 (2) pp 1236-1242, (2011).

2. A.A. Ismaeel, H.H. AI-Kayiem, A.T. Baheta and M.A. Aurybi. IET Renewable power generation, DOI:10.1049/ iet- rpg.2017-0058, (2017)

3. L.M. Michaud. Atmospheric Research, 39, PP157-78, (1995)

4. A. Varaksin, M.E. Romash, V.N. Kopeitsev and M.A. Gorbachev. International Journal of Heat and Transfer, 55 (23-24), pp6567-6572, (2012).

5. A. Varaksin, M.E. Romash and V.N. Kopeitsev. 14th European Turbulence Conference, France, 1-4 September, (2013).

6. H.S. Takhar and O.A. Beg. International Journal of Fluid Mechanics Research, 32 (4), (2005).

7. H.H. AI-Kayiem and A.T. Mustafa, Solar Vortex Engine, Malaysia. Patent No PI2015702890, 2015.

8. H. H. Al-Kayiem, A. T. Mustafa \& S. I. U. Gilani. WIT Transactions on Ecology and The Environment, 205, 193-202. (2016) http://dx.doi.org/10.2495/EQ160181

9. H.F. Joe land P.E. Milovan. Third edition book Publications: Springer, (2002).

10. ANSYS Fluent Software 15 Help User Guideline. 